\title{
Correction to: Testing an Explicit Method for Multi-compartment Neuron Model Simulation on a GPU
}

\author{
Taira Kobayashi $^{1}$ (]) $\cdot$ Rin Kuriyama ${ }^{1} \cdot$ Tadashi Yamazaki $^{1}$
}

Published online: 2 March 2022

○) Springer Science+Business Media, LLC, part of Springer Nature 2022

\section{Correction to: Current Psychology https://doi.org/10.1007/s12559-021-09942-6}

The article "Testing an Explicit Method for Multi-compartment Neuron Model Simulation on a GPU", written by Taira Kobayashi, Rin Kuriyama, Tadashi Yamazaki, was originally published online on the publisher's internet portal on 4 December 2021 with Open Access under a Creative Commons Attribution 4.0 International License.

With the author's/authors' decision to cancel Open Access the copyright of the article changed on 18 March 2022 to $($ )
Springer Science+Business Media, LLC, part of Springer Nature 2022 with all rights reserved.

The original article has been corrected.

Publisher's Note Springer Nature remains neutral with regard to jurisdictional claims in published maps and institutional affiliations.

The original article can be found online at https://doi.org/10.1007/ s12559-021-09942-6.

Tadashi Yamazaki

contact21@numericalbrain.org

Rin Kuriyama

rin.kuriyama@uec.ac.jp

1 Graduate School of Informatics and Engineering, The

University of Electro-Communications, 1-5-1 Chofugaoka,

Chofu, 182-8585, Tokyo, Japan 